\title{
ortho-Quinone amines and derivatives: the influence of structure on the rates and modes of intramolecular reaction
}

\author{
Edward J. Land ${ }^{a}$, Christopher A. Ramsden, ${ }^{a^{* \dagger}}$ and Patrick A. Riley ${ }^{b}$ \\ ${ }^{a}$ Lennard-Jones Laboratories, School of Physical and Geographical Sciences, Keele University, \\ Staffordshire ST5 5BG, United Kingdom \\ ${ }^{b}$ Totteridge Institute for Advanced Studies, The Grange, Grange Avenue, \\ London N20 8AB, United Kingdom \\ E-mail: c.a.ramsden@chem.keele.ac.uk
}

\begin{abstract}
The influence of $N$-substituents and chain length on the mode and rate of intramolecular reaction of ortho-quinone amines is reviewed. These reactions have been the subject of a series of studies over the last decade using a combination of pulse radiolysis, enzyme oximetry and preparative chemistry. Alternative reactions are cyclisation, spirocyclisation and para-quinomethane formation. The observed mode of reaction is determined by both the length of the ortho-quinone side chain and the nature of the $N$-substituents. The rates of the competing reactions are discussed and compared with rates determined by other workers using cyclic voltammetry. Formation of a para-quinomethane is relatively slow and only occurs when cyclisation is unfavourable due to steric, entropy or electronic effects. Spirocyclisation is rapid and usually reversible but in one case a stable spirocyclic product has been isolated.
\end{abstract}

Keywords: ortho-Quinones, para-quinomethanes, catechols, amines, cyclisation, spirocyclisation, rate constants

\section{Introduction}

Over the last decade we have used a variety of techniques to study the chemistry of orthoquinone amines $\mathbf{1}^{1}$ In particular we have generated reactive ortho-quinones by (i) tyrosinase oxidation of catechols 2 and phenols 3,, (ii) chemical oxidation of catechols 2 using 2,3dichloro-5,6-dicyano-1,4-benzoquinone (DDQ) or dianisyltellurium oxide (DAT), ${ }^{4,5}$ and (iii) disproportionation of semi-quinones $\mathbf{4}$, formed by pulse radiolysis of catechol solutions (Scheme 1). ${ }^{6}$ The chemistry of the formation and reactions of these ortho-quinones $\mathbf{1}$ has been monitored

\footnotetext{
${ }^{\dagger}$ Chris Ramsden was Chairman of the RSC Heterocyclic Group during the period 1995-1997
} 
by UV-Vis and ${ }^{1} \mathrm{H}$ NMR spectroscopy and the use of pulse radiolysis has enabled us to study reactive intermediates with very short half-lives $(10 \mathrm{~ms}-10 \mathrm{~s})$. When possible, novel reaction products have been isolated and fully characterised. This multidisciplinary approach has enabled us to recognise a consistent pattern of quinone amine behaviour in which the competing pathways and outcome are dependent on the side-chain structure. The pulse radiolysis studies have provided rate constants for a variety of intramolecular cyclisations and this presents the opportunity for a quantitative analysis of the influence of amine structure on cyclisation rate. These results have been reported in a series of publications in both the chemical and biological literature. The purpose of this account is to bring together all the relevant rate data and provide an overview of the structure-reactivity relationships in ortho-quinone amine chemistry. The absolute and relative rates of these competing reactions should also be of general interest.

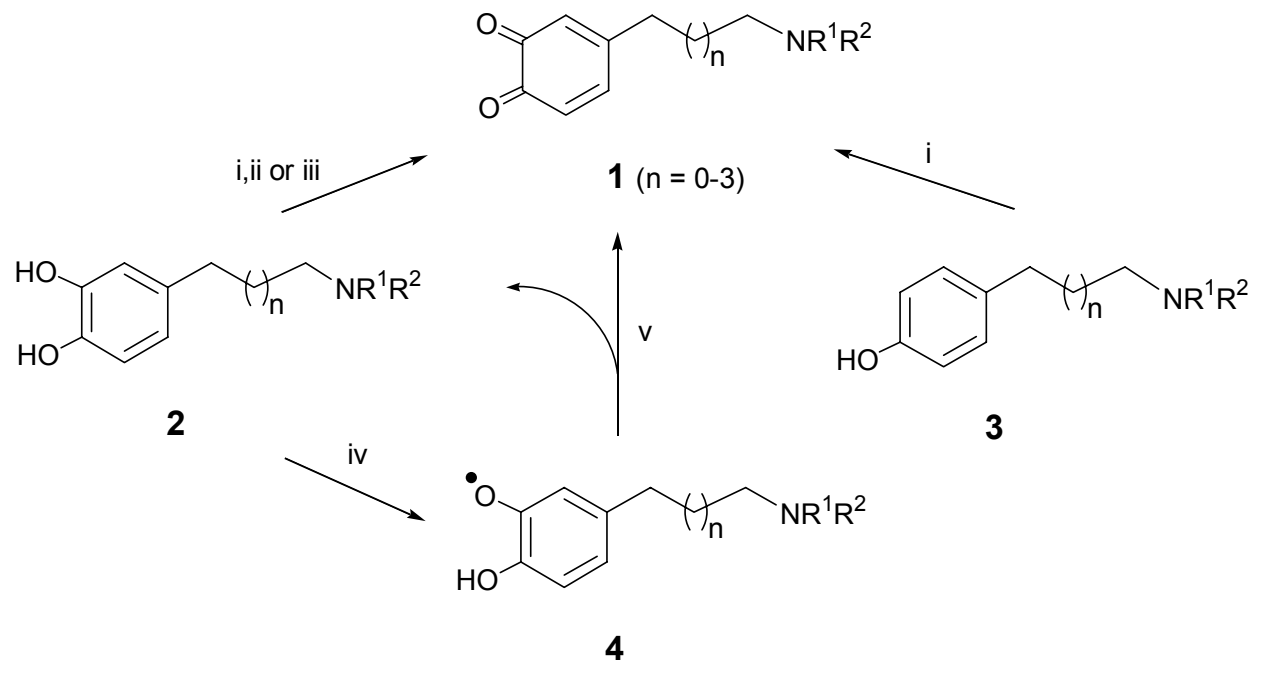

Reagents: i, tyrosinase; ii, DDQ; iii, DAT; iv, $\mathrm{Br}_{2}{ }^{-{ }^{-}}$or $\mathrm{N}_{3}{ }^{*}$; v, semiquinone 4

\section{Scheme 1}

Catechol and phenol amines (e.g. $\mathbf{2}$ and $\mathbf{3}$ ) have a wide variety of biological functions and include hormones (adrenaline, noradrenaline), neurotransmitters (dopamine), aminoacids (tyrosine), melanin precursors (dopa, cysteinyldopa), biological tools (naloxone) and therapeutic agents (isoproterenol, dopexamine, carbidopa, morphine). Their oxidation products include ortho-quinones and, in spite of the biological importance of their precursors, surprisingly little work has been reported on the chemistry of the derivatives $\mathbf{1}$ in which the chain length (n) and the substituents $\left(R^{1} R^{2}\right)$ have been varied. We have been particularly interested in the derivatives $\mathbf{2}$ and $\mathbf{3}$ as substrates for the enzyme tyrosinase and the use of specific derivatives as tools for investigating the mechanism of tyrosinase oxidation. ${ }^{1}$ 


\section{Discussion}

\subsection{The alternative modes of reaction}

During our work we have recognised four possible modes of intramolecular reaction of the quinone amines 1 and these are shown in Scheme 2. We have observed examples of three of these modes of reaction.
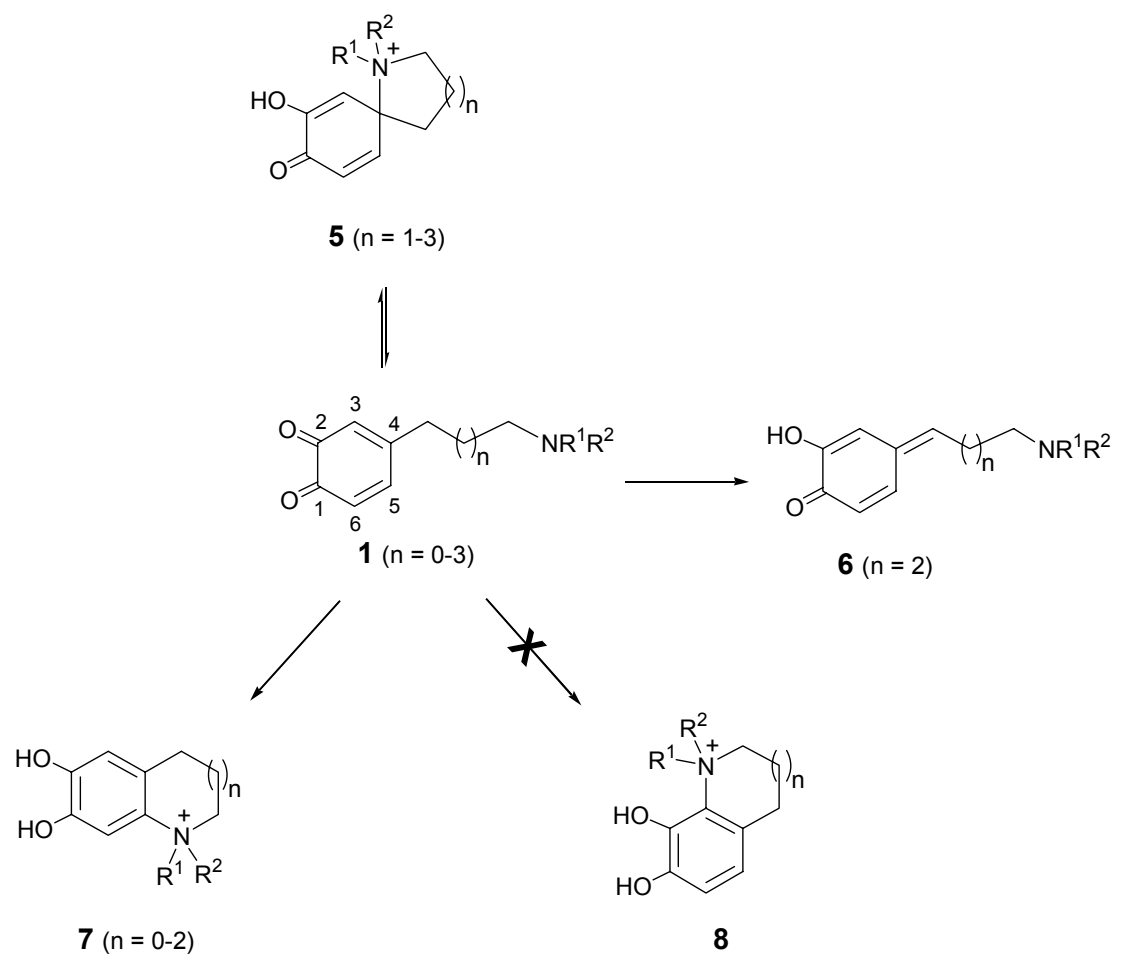

\section{Scheme 2}

The usual thermodynamic product is the catecholic quaternary cation 7 formed by intramolecular cyclisation at position 5 of the 4-substituted ortho-quinone 1. Formation of the product 7 is often preceded by rapid spirocyclisation to give product 5 but usually this kinetic product rapidly decays as the thermodynamic product 7 forms. Spirocyclisation and subsequent decay, via the reverse process $(5 \rightleftarrows \mathbf{1})$, are usually so fast that the intermediates can only be observed using pulse radiolysis. However, we have recently prepared a stable spirocyclic product (see Section 2.4). ${ }^{4}$

Isomerisation of the ortho-quinones $\mathbf{1}$ to the para-quinomethanes $\mathbf{6}$ is a relatively slow process and we have observed that this mode of reaction only occurs when the alternative cyclisation reactions are unfavourable.

It is interesting to note that in none of our studies have we observed the bicyclic catechol derivatives 8 formed by intramolecular cyclisation to position 3 of the 4-substituted ortho- 
quinones 1. We have been offered a variety of opinions as to why the products 8 are not observed. To explore the origins of this regioselectivity we investigated the alternative modes of intramolecular cyclisation using quantum mechanical calculations. ${ }^{7}$ These calculations suggest that for five-membered ring formation $(\mathbf{1} \rightarrow \mathbf{7}$ or $\mathbf{8}, \mathrm{n}=0)$ the trajectory of the amine attack is closer to the optimum direction for cyclisation to position 5. Figure 1 shows the calculated transition state structures for the alternative modes of cyclisation for five-membered ring formation. The yellow dummy atoms show the calculated optimal angle for nucleophilic attack. For intramolecular attack at positions 5 and 3 the deviations from the optimal angles are $12^{\circ}$ and $18^{\circ}$ respectively. As the ring size increases $(n>0)$ the trajectories for both modes of reaction approach the optimal angle but reaction at position 5 is still preferred. It appears that constraint on the angle of attack may contribute to the regioselectivity of intramolecular cyclisation for small rings but that this is not the major contribution.
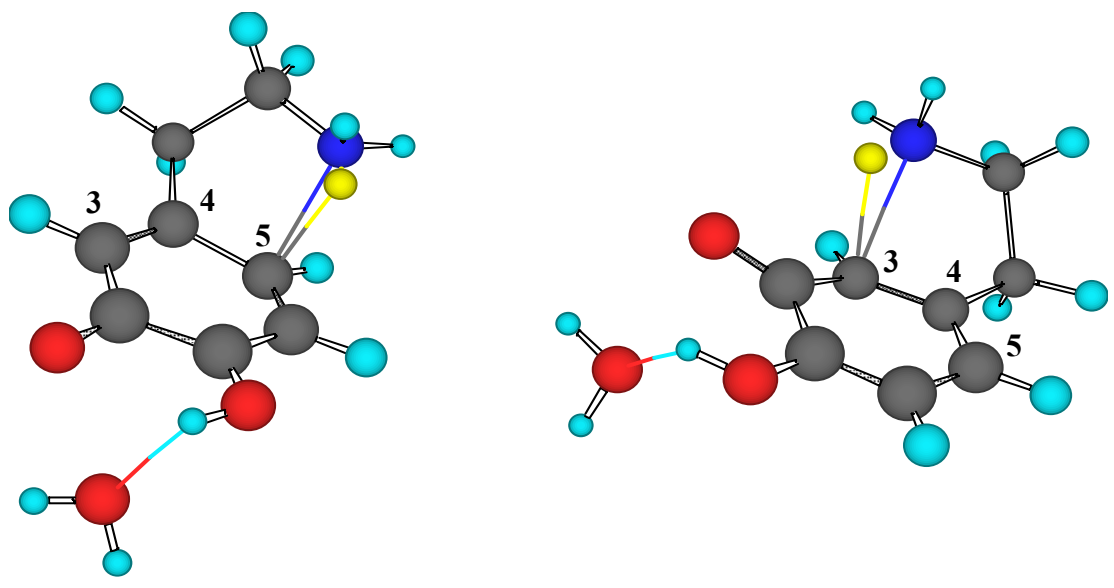

Figure 1. Calculated transition states for five-membered ring formation at positions 5 and 3 . The yellow dummy atom indicates the optimal angle of attack (Reprinted from Tetrahedron, 62, E. J. Land, C. A. Ramsden and P. A. Riley, An MO study of regioselective amine addition, 48844891, Copyright (2006), with permission from Elsevier).

MO calculations suggest that the major contribution to the regioselectivity of the intramolecular cyclisations is the intrinsic difference in the electronic energies of the conjugated systems in the alternative transition states 9 and 10. For cyclisation at position 5 only one C-C double bond is partially broken in the transition state 9 and an $\alpha, \beta$-unsaturated ketone function remains unperturbed. In the transition state $\mathbf{1 0}$ leading to cyclisation at position 3 both orthoquinone $\mathrm{C}-\mathrm{C}$ double bonds are partially broken leading to a significantly higher activation energy. 


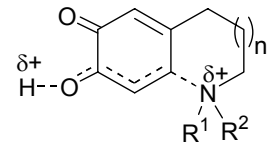

9

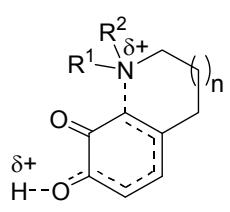

10

\subsection{The influence of chain length}

Many of our studies of the mechanism of tyrosinase oxidation have been carried out using tertiary amine derivatives $\left(1 ; n=0-3, R^{1}=R^{2} \neq H\right)$. The discussion of the influence of chain length in this section is therefore restricted to results using tertiary amines so that direct comparisons can be made. There are some significant differences in behaviour by secondary and primary amines and these are discussed in Section 2.3.

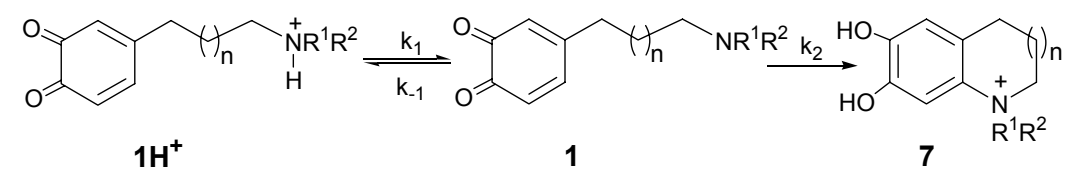

\section{Scheme 3}

In aqueous buffer, which is particularly relevant to biochemical transformations, the amines $\mathbf{1}$ are in equilibrium with the protonated species $\mathbf{1 H}^{+}$(Scheme 3 ). The rate of orthoquinone cyclisation measured by pulse radiolysis study of ortho-quinone decay is a function of the rate constants $\mathrm{k}_{1}, \mathrm{k}_{-1}$ and $\mathrm{k}_{2}$, and the $\mathrm{pH}$ of the solution. By applying the steady state approximation at $\mathrm{pH} \leq 7$, the overall rate constant $\left(\mathrm{k}_{\mathrm{d}}\right)$ for ortho-quinone decay is given by Equation (1). ${ }^{11}$ From Equation (1) it can be seen that the observed rate of ortho-quinone decay is a function of the base strength of the amine $\left(\mathrm{pK}_{\mathrm{a}}\right)$, ease of nucleophilic cyclisation of the amine and the $\mathrm{pH}$. At low $\mathrm{pH}$ pseudo first order deprotonation $\left(\mathrm{k}_{1}\right)$ of the quaternary salt is slow and cyclisation $\left(\mathrm{k}_{2}\right)$ is relatively fast (see Section 2.3). At higher $\mathrm{pH}(>7)$ base catalysed second order deprotonation becomes increasingly significant and the rate of the overall reaction $\left(\mathrm{k}_{\mathrm{d}}\right)$ increases further as the $\mathrm{pH}$ increases. The $\mathrm{pH}$ at which pulse radiolysis measurements are made depends upon a number of factors, including the physical characteristics of individual compounds, and it is not always possible to compare measurements at the same $\mathrm{pH}$. Kinetic data for ortho-quinone amines are given in Tables 1-3, where $\mathrm{k}_{\mathrm{d}}$ is the rate constant for ortho-quinone decay and $\mathrm{k}_{\mathrm{f}}$ is the rate constant for formation of the final product: for Scheme $3, \mathrm{k}_{\mathrm{d}}=-\mathrm{k}_{\mathrm{f}}$.

$$
\mathrm{k}_{\mathrm{d}}=\frac{\mathrm{k}_{1} \mathrm{k}_{2}}{\mathrm{k}_{-1}\left[\mathrm{H}_{3} \mathrm{O}^{+}\right]+\mathrm{k}_{2}}
$$

Inspection of Table 1 shows that the $N, N$-dialkyl derivatives of dopamine $11(\mathrm{R}=\mathrm{Me}, \mathrm{nPr})$ rapidly cyclise to give the quaternary cations $\mathbf{1 2}$. The rate constants measured using pulse radiolysis show that the di- $n$-propyl derivative cyclises more slowly than the dimethyl derivative. 
The small difference in $\mathrm{pH}$ together with a slightly higher $\mathrm{pKa}$ value for the di- $n$-propyl derivative $\left[c f \mathrm{nPrMe}_{2} \mathrm{~N}\right.$ ( $\mathrm{pKa}$ 9.99) and $\mathrm{nPr}_{3} \mathrm{~N}(\mathrm{pKa} 10.65)^{8}$ ] probably contribute to the difference in rate constants. However, a steric effect making the $\mathrm{N}(\mathrm{nPr})_{2}$ group a poorer nucleophile probably also makes a significant contribution.

The higher homologue $13(\mathrm{R}=\mathrm{Et})$ also rapidly cyclises at a comparable rate but here the initial reaction is spirocyclisation giving the product $14(\mathrm{R}=\mathrm{Et})$. This kinetically preferred product 14 in turn decays unimolecularly over several hundred milliseconds $\left(k_{f} 7.1 \mathrm{~s}^{-1}\right)$ to give the thermodynamic product $\mathbf{1 5}(\mathrm{R}=\mathrm{Et})$. The slower formation of products $\mathbf{1 5}$ compared to products $\mathbf{1 2}$ is partially attributable to the reduction in activation entropy on going to the larger ring.

Table 1. Tertiary amine kinetic data

\begin{tabular}{|c|c|c|c|c|c|c|c|}
\hline \multirow[t]{2}{*}{ Quinone } & \multicolumn{7}{|c|}{ Product } \\
\hline & $\mathrm{R}$ & $\mathrm{k}_{\mathrm{d}}$ & $\mathrm{pH}$ & Initial & Final & $\mathrm{k}_{\mathrm{f}}$ & Ref \\
\hline 11 & $\begin{array}{l}\mathrm{Me} \\
\mathrm{nPr}\end{array}$ & $\begin{array}{r}300 \mathrm{~s}^{-1} \\
48 \mathrm{~s}^{-1}\end{array}$ & $\begin{array}{l}6.2 \\
6.0\end{array}$ & & & - & $\begin{array}{r}{[5]} \\
{[10]}\end{array}$ \\
\hline 13 & $\mathrm{Et}$ & $230 \mathrm{~s}^{-1}$ & 6.2 & & & 7.1 & {$[5]$} \\
\hline & Et & $<0.1 \mathrm{~s}^{-1}$ & 6.2 & & & - & [9] \\
\hline & $\mathrm{nPr}$ & $<10^{-4} \mathrm{~s}^{-1}$ & $\mathrm{a}$ & & & - & [9] \\
\hline
\end{tabular}

${ }^{\mathrm{a}} \mathrm{In} \mathrm{CHCl}_{3} / \mathrm{MeOH}$ solution

It is significant to note that the next higher homologue $16(\mathrm{R}=\mathrm{Et})$ does not cyclise. There was no pulse radiolysis evidence that the ortho-quinone $16(\mathrm{R}=\mathrm{Et})$ formed a transient spirocyclic product. In fact this ortho-quinone $16(\mathrm{R}=\mathrm{Et})$ was observed to be stable over a period of more than ten seconds. This lack of formation of a spiro derivative is surprising in view of the fact that the corresponding secondary amines do undergo spirocyclisation (Section 2.3) and we conclude that steric interactions inhibit reaction. Since both possible modes of cyclisation are unfavourable for the derivative $16(\mathrm{R}=\mathrm{Et})$, a much slower alternative reaction can compete and this is tautomerisation to the para-quinomethane $\mathbf{1 7}(\mathrm{R}=\mathrm{Et})$. This reaction may proceed via initial intramolecular deprotonation by the amine. The final product, observed using ${ }^{1} \mathrm{H} N \mathrm{NR}$ 
and isolated as a salt, ${ }^{9}$ is the quaternary cation $\mathbf{1 8}$, which is formed by 5-exo-trig intramolecular cyclisation of the para-quinomethane $17(\mathrm{R}=\mathrm{Et})$.

Finally, when monitored by ${ }^{1} \mathrm{H}$ NMR the amine $19(\mathrm{R}=\mathrm{nPr})$ showed no evidence of cyclisation or tautomerism. The chain is too long for the amine to react intramolecularly as either nucleophile or base.

It is clear that for tertiary aminoalkyl ortho-quinones the chain length strongly influences both the initial mode of reaction and the structure of the final product. Although pulse radiolysis studies, and tyrosinase oxidation studies, were carried out in buffered aqueous solutions we have consistently found that the same modes of reaction and final products are observed in organic solvents.

Table 2. Primary amine kinetic data

\begin{tabular}{|c|c|c|c|c|c|c|c|}
\hline \multirow[t]{2}{*}{ Quinone } & \multicolumn{7}{|c|}{ Product } \\
\hline & $\mathrm{R}$ & $\mathrm{k}_{\mathrm{d}}$ & $\mathrm{pH}$ & Initial & Final & $\mathrm{k}_{\mathrm{f}}$ & Ref \\
\hline & - & $\begin{array}{c}0.04 \mathrm{~s}^{-1} \\
0.04 \mathrm{~s}^{-1} \\
0.35 \mathrm{~s}^{-1} \\
1.6 \mathrm{~s}^{-1}\end{array}$ & $\begin{array}{l}6.0 \\
7.0 \\
7.4 \\
8.0\end{array}$ & & & $\begin{array}{l}- \\
- \\
- \\
-\end{array}$ & $\begin{array}{r}{[11]} \\
{[12]} \\
{[3]} \\
{[3]}\end{array}$ \\
\hline & - & $\begin{array}{l}0.2 \mathrm{~s}^{-1} \\
0.9 \mathrm{~s}^{-1} \\
7.6 \mathrm{~s}^{-1} \\
23 \mathrm{~s}^{-1} \\
3.8 \mathrm{~s}^{-1} \\
-\end{array}$ & $\begin{array}{l}5.6 \\
6.6 \\
7.6 \\
8.6 \\
7.4 \\
6.0\end{array}$ & & & $\begin{array}{l}0.2 \mathrm{~s}^{-1} \\
0.99 \mathrm{~s}^{-1} \\
6.9 \mathrm{~s}^{-1} \\
23 \mathrm{~s}^{-1} \\
- \\
0.15 \mathrm{~s}^{-1}\end{array}$ & $\begin{array}{l}{[13]} \\
{[13]} \\
{[13]} \\
{[13]} \\
{[14]} \\
{[15-17]}\end{array}$ \\
\hline 25 & - & $0.04 \mathrm{~s}^{-1}$ & 6.0 & & & - & [11] \\
\hline 26 & $\begin{array}{l}\mathrm{OH} \\
\mathrm{Me}\end{array}$ & $\begin{array}{l}0.06 \mathrm{~s}^{-1} \\
0.07 \mathrm{~s}^{-1} \\
0.15 \mathrm{~s}^{-1} \\
0.36 \mathrm{~s}^{-1} \\
0.08 \mathrm{~s}^{-1}\end{array}$ & $\begin{array}{l}6.0 \\
6.0 \\
6.5 \\
7.0 \\
6.0\end{array}$ & & & $\begin{array}{l}- \\
- \\
- \\
- \\
-\end{array}$ & $\begin{array}{l}{[11]} \\
{[12]} \\
{[12]} \\
{[12]} \\
{[11]}\end{array}$ \\
\hline 27 & $\mathrm{Me}$ & $\begin{array}{l}0.02 \mathrm{~s}^{-1} \\
0.12 \mathrm{~s}^{-1} \\
0.50 \mathrm{~s}^{-1}\end{array}$ & $\begin{array}{l}5.0 \\
6.0 \\
7.0\end{array}$ & & & $\begin{array}{l}- \\
- \\
-\end{array}$ & $\begin{array}{l}{[12]} \\
{[12]} \\
{[12]}\end{array}$ \\
\hline
\end{tabular}




\subsection{Primary, secondary and tertiary amines}

Because of the importance of the cyclisation of the primary amine dopaquinone $\mathbf{2 3}$ to cyclodopa 24 in the early stages of the biosynthesis of melanin (Scheme 4), ${ }^{20,21}$ a number of studies of this type of cyclisation have been reported. Some measurements have been made by pulse radiolysis and others by cyclic voltammetry (Tables 2 and 3). Under enzymatic conditions the cyclisation product, e.g. 24, is usually rapidly oxidized by redox exchange with the precursor ortho-quinone to give a 'chrome', e.g. dopachrome (Scheme 4). This contrasts with the tertiary amines 11 (Table 1) where the powerful electron-withdrawing effect of the quaternary ammonium substituent in the cyclisation product, e.g. 12, makes oxidation to the ortho-quinone by redox exchange unfavourable.

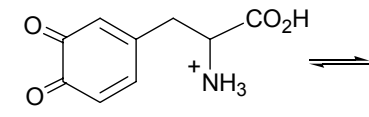

$23 \mathrm{H}^{+}$
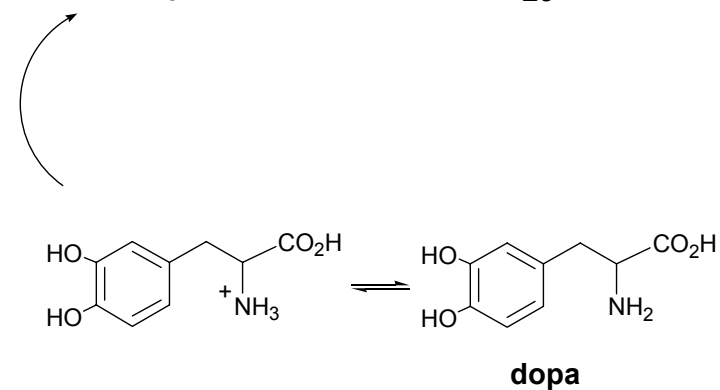

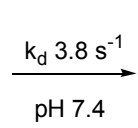

23
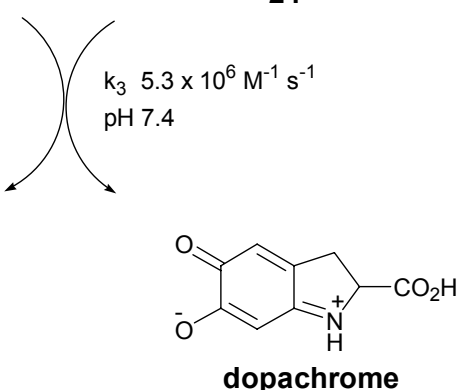

\section{Scheme 4}

Even at higher $\mathrm{pH}(7.4$ vs 6.0) the rate constant for decay of the ortho-quinone of dopamine $20\left(\mathrm{k}_{\mathrm{d}} 0.35 \mathrm{~s}^{-1}\right)$ is much lower than that for the tertiary amines $\mathbf{1 1}\left(\mathrm{k}_{\mathrm{d}} \sim 50-300 \mathrm{~s}^{-1}\right)$. This can probably be attributed to the primary amine being a stronger base (dopamine $\mathrm{pKa} 10.6$ ${ }^{22,23}$ ) but a poorer nucleophile than the tertiary amines $\mathbf{1 1}$ in aqueous solution. The pKa values of the tertiary amines have not been measured. As for other derivatives, the initial cyclisation product $\mathbf{2 1}$ is readily oxidised to the 'aminochrome' 22, either by redox exchange or aerial oxidation. $^{21}$

The most accurate measurement of the rate constant for decay of dopaquinone 23 is $3.8 \mathrm{~s}^{-1}$

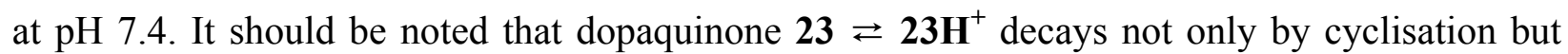
also by redox exchange $\left(\mathrm{k}_{3} 5.3 \times 10^{6} \mathrm{M}^{-1} \mathrm{~s}^{-1}\right.$ at $\mathrm{pH}$ 7.4) with its cyclisation product 24 (Scheme 4) and this competing reaction has to be taken into account when evaluating the kinetics. ${ }^{14}$ For this reason some earlier studies probably over-estimate the rate constant for cyclisation by a factor of 2 .

The rate constant measured for decay of dopaquinone $23\left(\mathrm{k}_{\mathrm{d}} 3.8 \mathrm{~s}^{-1}\right.$ at $\left.\mathrm{pH} 7.4\right)$ is significantly faster than that for the ortho-quinone of dopamine $20\left(\mathrm{k}_{\mathrm{d}} 0.35 \mathrm{~s}^{-1}\right.$ at $\left.\mathrm{pH} 7.4\right)$. This 
can be attributed to the inductive electron-withdrawing effect of the $\mathrm{CO}_{2} \mathrm{H}$ group reducing the basicity of the amine (dopa pKa $8.72^{22,23}$ ). Similar rate constants have been measured for the ortho-quinones of $\alpha$-methyldopamine 25 , noradrenaline $26(\mathrm{R}=\mathrm{OH})$ and $\alpha$-methylnoradrenaline $27(\mathrm{R}=\mathrm{Me})($ Table 2$)$.

In a series of detailed studies using cyclic voltammetry Young and coworkers investigated the thermodynamics and kinetics of the cyclisation of various catechol amines including dopamine and L-dopa. ${ }^{15,16,17}$ These studies provided the first order rate constants for the cyclisation of the free amines $\left(\mathrm{k}_{2}\right.$, Scheme 3$)$ as well as the overall rate constants for aminochrome formation $\left(\mathrm{k}_{\mathrm{f}}\right.$, Table 2). At $25{ }^{\circ} \mathrm{C}$ the measured rate constants and activation thermodynamic parameters were as follows: ortho-quinone of dopamine $(\mathbf{2 0} \rightarrow \mathbf{2 1})\left(\mathrm{k}_{2}=25.6 \mathrm{~s}^{-1}\right.$; $\left.\Delta \mathrm{G}^{\ddagger}=15.5 \mathrm{kcal} \mathrm{mol}^{-1} ; \Delta \mathrm{H}^{\ddagger}=21.4 \mathrm{kcal} \mathrm{mol}^{-1} ; \Delta \mathrm{S}^{\ddagger}=19.8 \mathrm{eu}\right)$ and dopaquinone $(\mathbf{2 3} \rightarrow \mathbf{2 4})\left(\mathrm{k}_{2}=\right.$ $\left.72 \mathrm{~s}^{-1} ; \Delta \mathrm{G}^{\ddagger}=14.9 \mathrm{kcal} \mathrm{mol}^{-1} ; \Delta \mathrm{H}^{\ddagger}=19.4 \mathrm{kcal} \mathrm{mol}^{-1} ; \Delta \mathrm{S}^{\ddagger}=15.1 \mathrm{eu}\right)$. In both cases the rate constants $\left(\mathrm{k}_{2}\right)$ indicate that cyclisation is fast compared to the overall process showing that under acidic conditions deprotonation $\left(\mathrm{k}_{1}\right.$, Scheme 3$)$ is the rate limiting process. Subsequently, a combined theoretical and kinetic study of the oxidation of L-dopa using mushroom tyrosinase under acidic conditions ( $\mathrm{pH}$ 5.0-6.0) was able to derive values of the rate constants for both the first order deprotonation step $\left(\mathrm{k}_{1}\right)$ and the cyclisation step $\left(\mathrm{k}_{2}\right)$ (Scheme 3$){ }^{24}$ The relevant parameters obtained at $25^{\circ} \mathrm{C}$ were as follows: deprotonation $\left(\mathrm{k}_{1}=0.41 \mathrm{~s}^{-1} ; \Delta \mathrm{G}^{*}=17.9 \mathrm{kcal} \mathrm{mol}^{-}\right.$ $\left.{ }^{1} ; \Delta \mathrm{H}^{\sharp}=21.0 \mathrm{kcal} \mathrm{mol}^{-1} ; \Delta \mathrm{S}^{\sharp}=10.4 \mathrm{eu}\right)$ and cyclisation $\left(\mathrm{k}_{2}=134 \mathrm{~s}^{-1} ; \Delta \mathrm{G}^{\sharp}=14.5 \mathrm{kcal} \mathrm{mol}^{-1} ; \Delta \mathrm{H}^{*}\right.$ $=22.6 \mathrm{kcal} \mathrm{mol}^{-1} ; \Delta \mathrm{S}^{\ddagger}=27.2 \mathrm{eu}$ ). Again the results at acidic $\mathrm{pH}$ are consistent with a slower deprotonation step followed by a more rapid cyclisation. It is noteworthy that both studies identify a large positive entropy of activation associated with a high probability factor for fivemembered ring formation.

As far as we are aware the kinetics of cyclisation of the next higher homologues of the ortho-quinone of dopamine $\mathbf{2 0}$ or dopaquinone $\mathbf{2 3}$ have not been studied. On the basis of an expected lower entropy of activation, the rate constants for cyclisation $\left(\mathrm{k}_{2}\right)$ can be expected to be smaller but to be preceded by fast spirocyclisation. The rate constants for deprotonation $\left(\mathrm{k}_{1}\right)$ should be similar to those for the lower homologues.

At $\mathrm{pH} 8.0$ the decay of the secondary ortho-quinone amine $28(\mathrm{R}=\mathrm{nPr})\left(\mathrm{k}_{\mathrm{d}}=384 \mathrm{~s}^{-}\right.$ $\left.{ }^{1}\right)$ (Table 3) is much faster than that of the corresponding primary amine $\mathbf{2 0}\left(\mathrm{k}_{\mathrm{d}}=1.6 \mathrm{~s}^{-1}\right)$ (Table 2). In aqueous solution these amines can be expected to have similar pKa values with the secondary amine probably being a slightly stronger base. At $\mathrm{pH} 8.0$ the deprotonation step will be much faster than at acidic $\mathrm{pH}$ and the faster rate of decay of the secondary amine $\mathbf{2 8}$ must therefore be attributable to it being a better nucleophile leading to faster cyclisation and consequently a much faster overall rate of decay. Other workers have observed the faster decay of secondary amines compared to primary amines. Adams and coworkers have shown that the cyclisation of adrenaline is 140 times faster than that of noradrenaline $(\operatorname{cf} \mathbf{2 9}(\mathrm{R}=\mathrm{Me})$ and $\mathbf{2 6}(\mathrm{R}$ $=\mathrm{OH}) .{ }^{12}$ Castagnoli and coworkers have observed that an $N$-methyl substituent very significantly increases the observed rate of cyclisation which they attribute to the increased nucleophilicity of the secondary amine. ${ }^{11}$ 
Table 3. Secondary amine kinetic data

\begin{tabular}{|c|c|c|c|c|c|c|c|}
\hline \multirow[t]{2}{*}{ Quinone } & & \multicolumn{6}{|c|}{ Product } \\
\hline & $\mathrm{R}$ & $\mathrm{k}_{\mathrm{d}}$ & $\mathrm{pH}$ & Initial & Final & $\mathrm{k}_{\mathrm{f}}$ & Ref \\
\hline & $\mathrm{Me}$ & $0.02 \mathrm{~s}^{-1}$ & 3.5 & & & - & [11] \\
\hline 28 & $\mathrm{nPr}$ & $384 \mathrm{~s}^{-1}$ & 8.0 & & & $238 \mathrm{~s}^{-1}$ & [18] \\
\hline & $\mathrm{Me}$ & $0.27 \mathrm{~s}^{-1}$ & 3.5 & & & - & [11] \\
\hline & & $0.10 \mathrm{~s}^{-1}$ & 4.0 & & & - & [12] \\
\hline 29 & & $0.99 \mathrm{~s}^{-1}$ & 5.0 & & & - & [12] \\
\hline & $i \operatorname{Pr}$ & $0.06 \mathrm{~s}^{-1}$ & 4.0 & & & - & [12] \\
\hline & & $0.15 \mathrm{~s}^{-1}$ & 5.0 & & & - & [12] \\
\hline & & $38 \mathrm{~s}^{-1}$ & 7.0 & & & - & [19] \\
\hline & $\mathrm{nPr}$ & $>1000 \mathrm{~s}^{-1}$ & 8.0 & & & $39 \mathrm{~s}^{-1}$ & [18] \\
\hline 30 & & - & 7.0 & & & $107 \mathrm{~s}^{-1}$ & [18] \\
\hline & $\mathrm{nPr}$ & - & 7.0 & & & $0.55 \mathrm{~s}^{-1}$ & [18] \\
\hline 33 & & $47 \mathrm{~s}^{-1}$ & 8.0 & & & $1.4 \mathrm{~s}^{-1}$ & [18] \\
\hline & $\mathrm{iPr}$ & $0.5 \mathrm{~s}^{-1}$ & 8.0 & 34 & & $0.5 \mathrm{~s}^{-1}$ & [18] \\
\hline & $\mathrm{tBu}$ & $<0.01 \mathrm{~s}^{-1}$ & 8.0 & & & - & [18] \\
\hline & $\mathrm{Me}$ & $<0.1 \mathrm{~s}^{-1}$ & 7.2 & & & - & [28] \\
\hline & - & $360 \mathrm{~s}^{-1}$ & 7.1 & & & - & [28] \\
\hline
\end{tabular}

At the same $\mathrm{pH}(\mathrm{pH} 8.0)$ the higher homologue $30(\mathrm{R}=\mathrm{nPr})$ very rapidly decays $\left(\mathrm{k}_{\mathrm{d}}>\right.$ $\left.1000 \mathrm{~s}^{-1}\right)$ to the spiro derivative $31(\mathrm{R}=\mathrm{nPr})$. This behaviour is comparable to that of the corresponding tertiary amine $\mathbf{1 3}(\mathrm{R}=\mathrm{Et})\left(\mathrm{k}_{\mathrm{d}}=230 \mathrm{~s}^{-1}\right.$ at $\mathrm{pH}$ 6.2) and, allowing for the difference in $\mathrm{pH}$ and substituent, the rate of ortho-quinone decay is similar. The spiro intermediate then 
decays more slowly to the catechol derivative $32\left(\mathrm{k}_{\mathrm{f}}=39 \mathrm{~s}^{-1}\right.$ at $\left.\mathrm{pH} 8.0\right)$. Interestingly, this transformation is faster at $\mathrm{pH} 7.0\left(\mathrm{k}_{\mathrm{f}}=107 \mathrm{~s}^{-1}\right)$, possibly because there is less deprotonation of the spiro intermediate $31 .{ }^{18}$ In this case it should be noted that the product $\mathbf{3 2}$ does not undergo further oxidation to the chrome by redox exchange (Table 3) because all the precursor orthoquinone is rapidly removed by spirocyclisation.

The next higher homologue $33(\mathrm{R}=\mathrm{nPr})$ also forms a spiro intermediate $\mathbf{3 4}(\mathrm{R}=\mathrm{nPr})$. This forms more slowly $\left(\mathrm{k}_{\mathrm{d}}=47 \mathrm{~s}^{-1}\right.$ at $\mathrm{pH}$ 8.0) than for the shorter chain $\mathbf{3 0}$ and this is attributable to the lower entropy of activation. Slower formation of the aminochrome $\mathbf{3 5}$ then occurs. This is in interesting contrast to the tertiary amine $16(\mathrm{R}=\mathrm{Et})$ which does not cyclise, presumably due to a steric effect. The corresponding iPr derivative $33(\mathrm{R}=\mathrm{iPr})$ decays significantly more slowly and we attribute this to a steric effect. In fact the $\mathrm{tBu}$ derivative $\mathbf{3 3}(\mathrm{R}=\mathrm{tBu})$ does not cyclise at all and chemical and enzyme studies indicate that, like the tertiary amine $16(\mathrm{R}=\mathrm{Et})$, it forms a para-quinomethane $36(\mathrm{R}=\mathrm{tBu})$ that can be trapped or which cyclises to a tetrahydropyrrole 37 . An MO study of the transition states for cyclisation of the amines $\mathbf{1 6}$ and $\mathbf{3 3}$ suggests that adverse interactions between protons on the alkyl chain disfavour cyclisation of the tertiary amines 16 and the $\mathrm{tBu}$ secondary amine $33(\mathrm{R}=\mathrm{tBu}){ }^{7}$ These interactions, measured by protonproton separations, appear to be smaller in the secondary amines $\mathbf{3 3}(\mathrm{R}=\mathrm{n}$-alkyl, $\mathrm{iPr})$ and this is consistent with the experimental observation of their cyclisations. Similar steric interactions of the alkyl chain protons are not present during cyclisation of the lower homologues. ${ }^{7}$

Two other secondary ortho-quinone amines $\mathbf{3 8}$ and $\mathbf{4 0}$ (Table 3), derived from the natural products salsolinol and tetrahydropapaveroline, have been studied by electrochemical, ${ }^{25,26}$ enzymatic $^{26,27}$ and pulse radiolytic ${ }^{28}$ oxidation. Both ortho-quinones may be responsible for neuronal damage in alcoholism. From electrochemical studies ${ }^{25}$ the ortho-quinone $\mathbf{3 8}$ has been proposed to isomerise in $\sim 1 \mathrm{~s}$ to the corresponding para-quinomethane 39, although the pulse radiolytic results ${ }^{28}$ suggest that the ortho-quinone has a lifetime of at least $10 \mathrm{~s}$. Pulse radiolytic oxidation of tetrahydropapaveroline ${ }^{28}$ leads to the ortho-quinone $\mathbf{4 0}$ which cyclises $\left(\mathrm{k}=360 \mathrm{~s}^{-1}\right)$ to the catechol $\mathbf{4 1}$ followed by rapid redox exchange giving the chrome $\mathbf{4 2}$.

\subsection{Other substituents}

An interest in potential anti-cancer pro-drugs, which could be activated by the tyrosinase in malignant melanoma, has led us to investigate the chemical and enzymatic oxidations of a number of catechol amine derivatives containing amine derived functional groups having a range of pKa values and nucleophilicities. The amide $\mathbf{4 3}$ and the urea $\mathbf{4 4}$ showed no tendency to cyclise and were stable over the pulse radiolysis timescale. ${ }^{3}$ However, combined oximetry and spectrophotometry studies showed evidence of first order isomerisation, with well-defined isosbestic points, giving the para-quinomethanes 45 and $\mathbf{4 6}$. These ortho-quinone to paraquinomethane rearrangements were found to have rate constants $\mathrm{k}_{\mathrm{d}} \approx 0.004 \mathrm{~s}^{-1}$ (amide) and $\mathrm{k}_{\mathrm{d}} \approx$ $0.0002 \mathrm{~s}^{-1}$ (urea) at $\mathrm{pH}$ 7.4. ${ }^{3}$ As discussed previously, these isomerisations are much slower than the rates of ortho-quinone cyclisation. In the case of derivatives $\mathbf{4 3}$ and $\mathbf{4 4}$ cyclisation does not occur because amides and ureas are poor nucleophiles. 
<smiles>CC(=O)NCCC1=CC(=O)C(=O)C=C1</smiles>

43

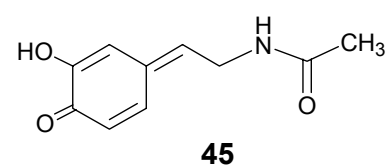<smiles>NC(=O)NCCC1=CC(=O)C(=O)C=C1</smiles>

44<smiles>NC(=O)NCC=C1C=CC(=O)C(O)=C1</smiles>

In contrast to the urea $\mathbf{4 4}$, the thiourea $\mathbf{4 7}$ cyclises $\left(\mathrm{k}_{\mathrm{d}} 1.7 \mathrm{~s}^{-1}\right.$ at $\left.\mathrm{pH} 8.0\right)$ to give the bicyclic derivative 48. ${ }^{3}$ Clearly the thiourea suphur is a good nucleophile and the rate of seven-membered ring formation is comparable to that observed for the corresponding secondary amines $\mathbf{3 3}$ (Table $3)$.

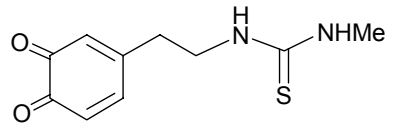

47

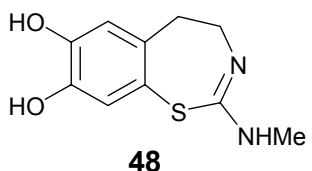

The guanidine 49 forms a stable ortho-quinone and shows no tendency to cyclise. ${ }^{4}$ However, the amidine $\mathbf{5 0}$ gave an unexpected result that was clearly observed by both UV-Vis and ${ }^{1} \mathrm{H}$ NMR spectroscopy. The ortho-quinone 50 was short lived and cyclised to the spiro derivative $51\left(\mathrm{k}_{\mathrm{d}} \approx 250 \mathrm{~s}^{-1} \text { at } \mathrm{pH} 8.0\right)^{3}$ which was stable and could be isolated and fully characterized. ${ }^{4}$ During our studies this is the only time we have encountered the formation of a stable spiro product ( $c f \mathbf{5}$, Scheme 2). We attribute the stability of the product to rapid and irreversible tautomerisation of the initial product $\mathbf{5 2}$ to the resonance stabilized 3-proto cation $\mathbf{5 1}$.<smiles>N=C(N)NCCC1=CC(=O)C(=O)C=C1</smiles>

49<smiles>O=C1C=CC2(C=C1)NCCC2=C(Cl)C(Cl)(Cl)Cl</smiles>

51<smiles>N=C(NCCC1=CC(=O)C(=O)C=C1)C(Cl)(Cl)Cl</smiles><smiles>O=C1C=CC2(C=C1)CCN=C(C(Cl)(Cl)Cl)N2</smiles>

52 


\section{Conclusions}

The ortho-quinone amine dopaquinone $\mathbf{2 3}$ is an important early intermediate in the biosynthesis of melanin pigments. Its reactions include intramolecular cyclisation, as well as redox exchange with catechols and addition of nucleophiles such as cysteine. ${ }^{2}$ As part of a study of the mechanism of action of the enzyme tyrosinase and an evaluation of tyrosinase substrates and inhibitors we have investigated the chemistry of a range of ortho-quinone amine derivatives. The modes and rates of the intramolecular reactions that we have observed depend on a number of factors. The rates of cyclisation depend primarily on the ring size, nucleophilicity of the functional group and $\mathrm{pH}$. Rates of cyclisation tend to increase along the series primary amine $<$ secondary amine < tertiary amine. Entropy favours spirocyclisation but this is usually, but not always (e.g. 51), reversible and the thermodynamic products are formed by cyclisation at position 5 (Scheme 2). When cyclisation is unfavourable a slower rearrangement to a paraquinomethane occurs. We are currently investigating other novel ortho-quinone amine derivatives with the object of further exploring these different modes of intramolecular reaction in order to prepare novel heterocyclic molecules.

\section{References and Notes}

1. Land, E. J.; Ramsden, C. A.; Riley, P. A. Acc. Chem. Res. 2003, 36, 300.

2. Land, E. J.; Ramsden, C. A.; Riley, P. A. Methods in Enzymology 2004, 378A, 88.

3. Borovansky, J.; Edge, R.; Land, E. J.; Navaratnam, S.; Pavel, S.; Ramsden, C. A.; Riley, P. A.; Smit, N. P. M. Pigment Cell Res. 2006, 19, 170.

4. Land, E. J.; Perona, A.; Ramsden, C. A.; Riley, P. A. Org. Biomol. Chem. 2005, 3, 2387.

5. Clews, J.; Cooksey, C. J.; Garratt, P. J.; Land, E. J.; Ramsden, C. A.; Riley, P.A. J. Chem. Soc., Perkin Trans 1 2000, 4306.

6. Land, E. J.; Ramsden, C. A.; Riley, P. A. J. Photochem. \& Photobiol. B: Biology 2001, 64, 123.

7. Land, E. J.; Ramsden, C. A.; Riley, P. A. Tetrahedron 2006, 62, 4884.

8. Hall, Jr., H. K. J. Amer. Chem. Soc. 1957, 79, 5441.

9. Land, E. J.; Ramsden, C. A.; Riley, P. A.; Yoganathan, G. Org. Biomol. Chem. 2003, 1, 3120 .

10. Cooksey, C. J.; Garratt, P. J.; Land, E. J.; Pavel, S.; Ramsden, C. A.; Riley, P. A.; Smit, N. P. M. J. Biol. Chem. 1997, 272, 26226.

11. Chavdarian, C. G.; Karashima, D.; Castagnoli, Jr., N. J. Med. Chem. 1978, 21, 548.

12. Hawley, M. D.; Tatawawadi, S. V.; Piekarski, S.; Adams, R. N. J. Am. Chem. Soc. 1967, 89, 447. 
13. Thompson, A.; Land, E. J.; Chedekel, M. R.; Subbarao, K. V.; Truscott, T. G. Biochim. Biophys. Acta 1985, 843, 49. Chedekel, M. R.; Land, E. J.; Thompson, A.; Truscott, T. G. J. C. S. Chem. Commun. 1984, 1170.

14. Land, E. J.; Ito, S.; Wakamatsu, K; Riley, P. A. Pig. Cell Res. 2003, 16, 487.

15. Young, T. E.; Griswold, J. R.; Hulbert, M. H. J. Org. Chem. 1974, 39, 1980.

16. Young, T. E.; Babbitt, B. W.; Wolfe, L. A. J. Org. Chem. 1980, 45, 2899.

17. Young, T. E.; Babbitt, B. W. J. Org. Chem. 1983, 48, 562.

18. Land, E. J.; Ramsden, C. A.; Riley, P. A.; Yoganathan, G. Pig. Cell Res. 2003, 16, 397.

19. Land E. J. unpublished results.

20. Land, E. J.; Ramsden, C. A.; Riley, P. A. In The Pigmentary System: Physiology and Pathophysiology 2nd Edition: Nordlund, J. J.; Boissy, R. E.; Hearing, V. J.; King, R. A.; Oetting, W. S.; Ortonne J-P.: Eds.; Blackwell Publishers: Oxford, 2006; pp 354-394.

21. D’Ischia, M.; Napolitano, A.; Pezzella, A.; Land, E. J.; Ramsden, C. A.; Riley, P. A. Adv. Heterocycl. Chem. 2005, 89, 1.

22. Handbook of Chemistry and Physics, Lide, D. R.; Ed-in-Chief, $86^{\text {th }}$ Edn.; CRC Press: Florida, 2005; Section 8-42.

23. Data for Biochemical Research, $3^{\text {rd }}$ Edn., Dawson, R. M. C.; Elliott, D. C.; Elliott, W. H.; Jones, K. M.; Eds., Clarendon Press: Oxford, 1986.

24. Garcia-Carmona, F.; Garcia-Cánovas, F.; Iborra, J. L.; Lozano, J. A. Biochim. Biophys. Acta 1982, 717, 124.

25. Fa, Z.; Dryhurst, G. Bioorganic Chem. 1991, 19, 384.

26. Zang, F.; Dryhurst, G. J. Org. Chem. 1991, 56, 7113.

27. Fa, Z.; Dryhurst, G. Biochem. Pharmacol. 1991, 42, 2208.

28. Land, E. J. J. Chem. Soc., Faraday Trans. 1993, 89, 803. 